\title{
Flexural Fracture Toughness and First-Crack Strength Tests of Steel Fiber-Silica Fume Concrete and Its Engineering Applications
}

\author{
J. P. Zhang, ${ }^{a}$ L. M. Liu, ${ }^{\text {a,1 }}$ Z. D. Zhu, ${ }^{\text {b }}$ F. T. Zhang, ${ }^{\text {c }}$ J. Z. Cao ${ }^{d}$ \\ a College of Mining and Safety Engineering, Shandong University of Science and Technology, \\ Qingdao, China \\ ${ }^{\mathrm{b}}$ Geotechnical Research Institute of Hohai University (GeoHohai), Nanjing, China \\ c Shandong Ark New Materials Co. Ltd., Tai'an, China \\ d Taian Ark Mining Ark Technology Co. Ltd., Tai'an, China \\ $12280840483 @ q q . c o m$
}

The effect of a steel fiber and silica fume on the first-crack strength and the flexural toughness of concrete is evaluated. The ten sets of specimens with a steel fiber content of $0,40,50$, and $60 \mathrm{~g} / \mathrm{m}^{3}$ and steel fiber types of wave shear and straight shear types with and without a silica fume content of a $10 \%$ replacement of the cement weight were tested. The results show that the combined effect of silica fume and steel fiber improve the first-crack load and deflection of specimens to a certain degree and increase the flexural fracture toughness of specimens greatly. In the strengthening effect of steel fiber silica fume concrete, the steel fiber is of first importance, while silica fume is an auxiliary component. The wet steel fiber-silica fume shotcrete support for controlling the surrounding rock mass can provide the whole supporting effect of the anchor mesh shotcrete.

Keywords: concrete, steel fiber, silica fume, first-crack load and deflection, flexural toughness.

Introduction. The wet shotcrete is widely used in the shotcrete operation of underground engineering, since, in contrast to dry shotcrete, it has the advantages of good working environment, high quality of concrete and low rebound rate [1, 2]. However, the common disadvantages of the existing wet shotcrete materials are: insufficient ductility and toughness and serious initial cracking [3,4]. Thus, the initial cracking control and the improvement its ductility and toughness are urgent problems to be solved.

The action mechanism of silica fume in concrete includes pozzolanic effect and microaggregate effect. Silica fume reacts with cement hydration product $\mathrm{Ca}(\mathrm{OH})_{2}$ to produce a hydrated calcium silicate gel. The strength of hydrated calcium silicate gel being higher than that of cement hydration product $\mathrm{Ca}(\mathrm{OH})_{2}$, silica fume can improve the structural strength of concrete $[5,6]$.

Incorporation of steel fibers into a brittle matrix is an efficient way to improve the flexural strength. Debonding, sliding, and fiber pullout are the local mechanisms that control the bridging action during both micro- and macrocracking of the matrix. These mechanisms increase the demand of energy for crack propagation [7, 8]. So, steel fiber can significantly improve the ductility and toughness of concrete by hindering the propagation of microcracks and improving the energy absorption capacity of concrete [9-11].

When silica fume and steel fiber are jointly used as admixture of concrete, there is a bonding interaction between them [12]. Multiple studies on the joint effect of silica fume and steel fiber on the improvement of concrete mechanical properties appeared in recent years. Thus, Mastali and Dalvand [13] investigated the effect of replacing cement with silica fume on the impact resistance and mechanical properties of self-compacting steel fiber-reinforced concrete. Arivalagan [14] explored the impact of silica fume on flexural behavior of self-compacting steel fiber-reinforced concrete. Gesoğlu et al. [15] studied the mechanical properties of the fly-ash concrete with added steel fiber and silica fume. 
The above scholars investigated the separate effect of silica fume or steel fibers on the mechanical properties of concrete, but not the joint effect [16-19]. There only few investigations on the combined action of silica fume and steel fiber and their effect on the first-crack strength and flexural fracture toughness of concrete [16-19]. In the underground engineering, the shotcrete support has higher requirements on the flexural toughness of concrete. Therefore, in order to solve the problem of insufficient ductility and toughness and serious initial cracking of the existing wet shotcrete materials, this paper investigates the combined effect of silica fume and steel fiber on the first-crack strength and flexural toughness of concrete. The optimum proportion of wet sprayed steel fiber-silica fume concrete is obtained. Then, the concrete material of optimum proportion was applied to the wet shotcrete support of roadway.

\section{Experimental.}

1.1. Materials and Concrete Mixture Design. In this study, ordinary Portland cement of CEM I 42.5R grade was adopted. The fine aggregates were obtained from the natural sands with the apparent density of $2650 \mathrm{~kg} / \mathrm{m}^{3}$ and the fineness modulus of 2.58 . The coarse aggregates were obtained from the pebble with the particle size of $6-10 \mathrm{~mm}$ and rounded particles. The round pebble particle can reduce the wear of cement spraying machine and conveying pipe. In addition, it can reduce the blockage fault. The water was obtained from tap water. Silica fume is produced by Elkem International Trade (Shanghai) Co., Ltd. Silica fume replacing cement is used as admixture. The chemical compositions and physical properties of silica fume are listed in Table 1. Steel fibers including wave shear type and straight shear type were produced by Jiaxing Jingwei Steel Fiber Co. Ltd. The physical parameters of steel fiber are listed in Table 2. In order to control the solidification time, the MNC-Q1 non-alkali liquid accelerated agent was used.

$\mathrm{T}$ a b 1 e 1

The Chemical Compositions and Physical Properties of Silica Fume

\begin{tabular}{|c|c|c|c|c|c|c|c||}
\hline \hline $\begin{array}{c}\text { Average } \\
\text { particle } \\
\text { size }(\mu \mathrm{m})\end{array}$ & $\begin{array}{c}\text { Specific } \\
\text { surface } \\
\text { area }\left(\mathrm{m}^{2} / \mathrm{kg}\right)\end{array}$ & Fineness & \multirow{2}{*}{$\begin{array}{c}\text { Density } \\
\left(\mathrm{g} / \mathrm{cm}^{3}\right)\end{array}$} & & \multicolumn{4}{|c|}{ Percentage content (\%) } \\
\cline { 5 - 8 } & & & Alkali & $\mathrm{SiO}_{2}$ & Loss & $\mathrm{Cl}$ \\
\hline 0.1 & 15000 & 0.05 & 2.3 & 1.23 & 93.2 & 1.15 & 0.012 \\
\hline
\end{tabular}

$\mathrm{T}$ a b 1 e 2

The Physical Parameters of Steel Fiber

\begin{tabular}{|c|c|c|c|c||}
\hline Steel fiber type & $\begin{array}{c}\text { Length } \\
(\mathrm{mm})\end{array}$ & $\begin{array}{c}\text { Equivalent } \\
\text { diameter }(\mathrm{mm})\end{array}$ & Aspect ratio & $\begin{array}{c}\text { Tensile strength } \\
(\mathrm{MPa})\end{array}$ \\
\hline Wave shear type & 30 & 0.3 & 100 & $>1150$ \\
\hline Straight shear type & 25 & 0.3 & 83 & $>1150$ \\
\hline
\end{tabular}

There are ten sets of tests, each consisting of three cuboid specimens $(100 \times 100 \times 400$ $\mathrm{mm})$. Based on the experience, the quality of each group was estimated at the density of $2400 \mathrm{~kg} / \mathrm{m}^{3}$, together with the quality loss in tests. According to the requirements for wet shotcrete in specifications for bolt-shotcrete support and the water absorption of sand, the cement-to-sand ratio was kept constant (equal to 1:2.4) for all mixtures. Reasonable waterto-cement ratio is helpful to reduce springback amount, reduce dust and guarantee the quality of wet shotcrete. The water-to-cement ratio (WCR) should not only ensure good fluidity and strength of steel fiber-silica fume concrete, but also exclude any segregation resulting in waste. The applied WCR was: $W_{w}: W_{c}: W_{s}$ (water: cement: sand) $=0.55: 1: 2.4$ $=0.139: 0.253: 0.608$. 
According to the above WCR, water-to-cement ratio was 0.55 , while setting accelerator content of $1.2 \mathrm{~kg} / \mathrm{m}^{3}$, pebble content of $584 \mathrm{~kg} / \mathrm{m}^{3}$, and sand content of $1105 \mathrm{~kg} / \mathrm{m}^{3}$. Ten groups of specimens with different steel fiber content of $0,40,50$, and $60 \mathrm{~g} / \mathrm{m}^{3}$ and different steel fiber shapes of wave and straight shear types with and without silica fume content of $10 \%$ replacement of the weight of cement were tested. Table 3 lists the material proportions of each group.

$\mathrm{T}$ a b 1 e 3

The Material Proportions of Each Group

\begin{tabular}{|c|c|c|c|c|c|c|c|c||}
\hline Group & WCR & $\begin{array}{c}\text { Setting } \\
\text { accelerator } \\
(\mathrm{RC}) \\
\left(\mathrm{kg} / \mathrm{m}^{3}\right)\end{array}$ & $\begin{array}{c}\text { Cement } \\
\text { content } \\
\left(\mathrm{kg} / \mathrm{m}^{3}\right)\end{array}$ & $\begin{array}{c}\text { Sands } \\
\text { content } \\
\left(\mathrm{kg} / \mathrm{m}^{3}\right)\end{array}$ & $\begin{array}{c}\text { Pebble } \\
\text { content } \\
\left(\mathrm{kg} / \mathrm{m}^{3}\right)\end{array}$ & $\begin{array}{c}\text { Silica } \\
\text { fume } \\
\left(\mathrm{kg} / \mathrm{m}^{3}\right)\end{array}$ & $\begin{array}{c}\text { Steel } \\
\text { fiber } \\
\text { type }\end{array}$ & $\begin{array}{c}\text { Steel } \\
\text { fiber } \\
\text { content } \\
\left(\mathrm{kg} / \mathrm{m}^{3}\right)\end{array}$ \\
\hline 1 & 0.55 & 1.2 & 460.40 & 1105 & 584 & 0 & Nothing & 0 \\
\hline 2 & 0.55 & 1.2 & 414.36 & 1105 & 584 & 46.04 & Nothing & 0 \\
\hline 3 & 0.55 & 1.2 & 460.40 & 1105 & 584 & 0 & $\begin{array}{c}\text { Wave } \\
\text { shear }\end{array}$ & 40 \\
\hline 4 & 0.55 & 1.2 & 460.40 & 1105 & 584 & 0 & $\begin{array}{c}\text { Straight } \\
\text { shear }\end{array}$ & 40 \\
\hline 5 & 0.55 & 1.2 & 414.36 & 1105 & 584 & 46.04 & $\begin{array}{c}\text { Wave } \\
\text { shear }\end{array}$ & 40 \\
\hline 6 & 0.55 & 1.2 & 414.36 & 1105 & 584 & 46.04 & $\begin{array}{c}\text { Straight } \\
\text { shear }\end{array}$ & 40 \\
\hline 7 & 0.55 & 1.2 & 414.36 & 1105 & 584 & 46.04 & $\begin{array}{c}\text { Wave } \\
\text { shear }\end{array}$ & 60 \\
\hline 8 & 0.55 & 1.2 & 414.36 & 1105 & 584 & 46.04 & $\begin{array}{c}\text { Straight } \\
\text { shear }\end{array}$ & 60 \\
\hline 9 & 0.55 & 1.2 & 414.36 & 1105 & 584 & 46.04 & $\begin{array}{c}\text { Wave } \\
\text { shear }\end{array}$ & 50 \\
\hline 10 & 0.55 & 1.2 & 414.36 & 1105 & 584 & 46.04 & $\begin{array}{c}\text { Shear } \\
\text { straight }\end{array}$ & 50 \\
\hline
\end{tabular}

1.2. Preparation and Testing of Specimens. The slump test of steel fiber-silica fume concrete and reference concrete was carried out. The slump of reference concrete is $176 \mathrm{~mm}$, the slump of steel fiber-silica fume concrete is $180 \mathrm{~mm}$, being very close to one another. The mixtures were prepared and agitated, according to the standard, by forced action mixer for $5 \mathrm{~min}$. Then, the obtained mixtures were cast into molds, vibrated and floated. According to the slump, the vibrating time was $60 \mathrm{~s}$. All specimens were stored at ambient temperature of $20^{\circ} \mathrm{C}$ and $75 \%$ relative humidity for $24 \mathrm{~h}$. Then, specimens were stripped and cured in the curing room at the temperature of $23^{\circ} \mathrm{C}$ for 28 days. After 28 days, all specimens were tested, in accordance with test methods for steel fiber-reinforced concrete CECS13:89.

The tests were carried out using a $300-\mathrm{kN}$ CSS44100 electronic universal testing machine. Before the initial crack detection, the loading rate was $0.05-0.08 \mathrm{MPa} / \mathrm{s}$; after the initial crack, the crack length extension $l / 3000$ was provided every minute, so that the deflection growth rate was equal. During the loading process, the deflection was recorded and the load-deflection curve was plotted. For each mix composition, three specimens were tested, and the average of the first-crack strength test and the flexural fracture toughness were presented. 
2. Results and Discussion. Flexural toughness index was calculated based on the experimental method of CECS13:89 steel fiber reinforced concrete. The elastic-perfectly plastic material was assumed as the reference standard of the material toughness. The multiple options $(3 \delta, 5.5 \delta$, and $15.5 \delta)$ of the first-crack deflection were used to determine the end-point deflection. The first-crack load and deflection of specimens were obtained directly. The flexural toughness index and the variation factor of flexural capacity of specimens were calculated using the load-deflection curve of concrete. Table 4 lists the test results of the first-crack strength and flexural fracture toughness of specimens.

$\mathrm{T}$ a b 1 e 4

The Test Results of the First-Crack Strength and the Flexural Toughness

\begin{tabular}{|c|c|c|c|c|c|c|c|c||}
\hline \hline Group & $\begin{array}{c}\text { First-crack } \\
\text { load } \\
(N)\end{array}$ & $\begin{array}{c}\text { First-crack } \\
\text { deflection } \\
(0.01 \mathrm{~mm})\end{array}$ & $I_{5}$ & $I_{10}$ & $I_{30}$ & $\xi_{m, n, 5}$ & $\xi_{m, n, 10}$ & $\xi_{m, n, 30}$ \\
\hline 1 & 4944 & 8.70 & 1.00 & 1.00 & 1.00 & 0 & 0 & 0 \\
\hline 2 & 5868 & 9.50 & 1.00 & 1.00 & 1.00 & 0 & 0 & 0 \\
\hline 3 & 6349 & 10.30 & 4.86 & 9.26 & 24.91 & 0.93 & 0.84 & 0.65 \\
\hline 4 & 6258 & 9.90 & 4.63 & 9.07 & 24.38 & 0.82 & 0.79 & 0.61 \\
\hline 5 & 6497 & 10.20 & 4.98 & 9.45 & 25.65 & 0.99 & 0.88 & 0.70 \\
\hline 6 & 6443 & 9.70 & 4.75 & 9.31 & 25.28 & 0.88 & 0.85 & 0.67 \\
\hline 7 & 6756 & 10.70 & 5.28 & 9.82 & 27.03 & 1.17 & 0.98 & 0.83 \\
\hline 8 & 6606 & 10.50 & 5.13 & 9.67 & 26.89 & 1.07 & 0.93 & 0.79 \\
\hline 9 & 6506 & 10.40 & 5.21 & 9.73 & 26.87 & 1.11 & 0.94 & 0.78 \\
\hline 10 & 6489 & 9.90 & 4.92 & 9.49 & 26.09 & 0.96 & 0.89 & 0.73 \\
\hline
\end{tabular}

2.1. First-Crack Load and Deflection. The results on the first-crack load and deflection are depicted in Table 4 and Fig. 1. In comparison with the reference concrete (group 1), the first-crack load and the first-crack deflection in the concrete mixture (group 2) with silica fume replacing $10 \%$ of cement weight increased by 18.7 and $9.2 \%$, respectively. Based on these results, the addition of wave or straight shear type steel fibers with the same specific weight of $40 \mathrm{~kg} / \mathrm{m}^{3}$ resulted in the increase of the first-crack load by 28.4 and $26.66 \%$ and the first-crack deflection by 18.4 and $13.8 \%$ for the concrete mixtures, respectively, as compared with the reference concrete. Thus, an increase in the content of steel fiber resulted in higher values of the first-crack load and deflection. In comparison with the reference concrete, increasing the wave shear type steel fiber content from 40 to 50 and $60 \mathrm{~kg} / \mathrm{m}^{3}$ (with $10 \%$ of silica fume) resulted in an increase in the first-crack load from 31.4 to 31.6 and $36.7 \%$, respectively, while the first-crack deflection grew from 17.2 to 19.5 and $23 \%$ for the concrete mixture, respectively. as compared with to the reference concrete.

In addition, a rise in the straight shear type steel fiber content from 40 to 50 and $60 \mathrm{~kg} / \mathrm{m}^{3}$ (with $10 \%$ silica fume) increased the first-crack load from 30.3 to 31.3 and $33.6 \%$, respectively, and the first-crack deflection from 11.5 to 13.8 and $20.7 \%$, respectively. When the steel fiber specific weight was $50 \mathrm{~kg} / \mathrm{m}^{3}$, the first-crack load of the wave shear type steel fiber concrete with $10 \%$ of silica fume was slightly larger than that of the straight 


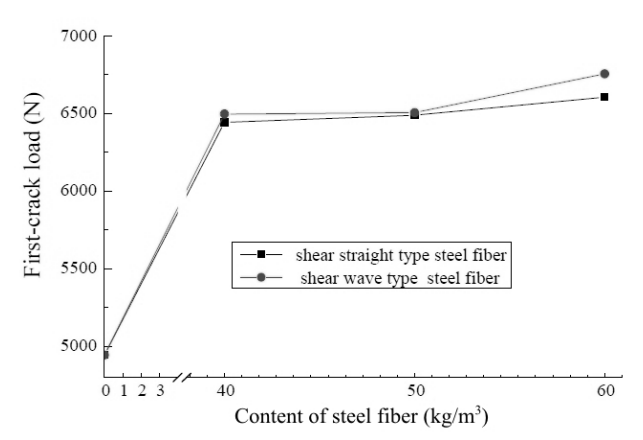

a

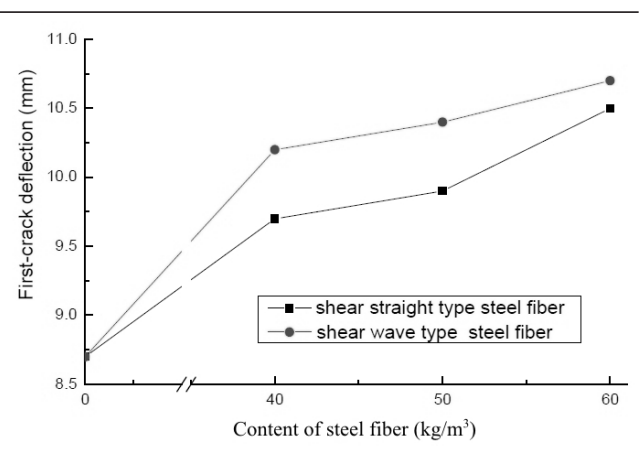

b

Fig. 1. Relationship between of the first-crack load (a) and deflection (b) of specimens and steel fiber content of $0,40,50$, and $60 \mathrm{~g} / \mathrm{m}^{3}$.

shear type one with $10 \%$ of silica fume. However, when the specific weight of steel fiber was $60 \mathrm{~kg} / \mathrm{m}^{3}$, the improvement in the first-crack load of the wave shear type steel fiber concrete with $10 \%$ of silica fume exceeded both that of the straight shear one with $10 \%$ of silica fume $10 \%$ and that with specific weight of $50 \mathrm{~kg} / \mathrm{m}^{3}$.

With the same content of steel fiber and silica fume and the same shape of steel fiber, the improvement in the first-crack load of concrete specimens was slightly larger than that of the first-crack deflection. With the same content of steel fiber and silica fume, the improvement in the first-crack load and deflection of the concrete with wave shear type steel fiber is slightly larger than that of that with straight shear type one. Thus, the effect of silica fume and steel fiber can partly improve the first-crack load and the first-crack deflection: with an increase in the steel fiber content, the first-crack load and the first-crack deflection of concrete increase gradually.

Steel fibers can delay the initial cracking time and increase the first-crack load and the first-crack deflection of concrete by improving its internal structure. Increasing steel fiber content in the concrete mixtures raises the energy consumption, overcomes the limitations of steel fibers, and enhances their strength. The silica fume and C-S-H gel generated by a secondary reaction can be added to the cement hardened paste, in order to improve its microstructure and partly increase the first-crack load and the first-crack deflection of concrete mixtures. When silica fume and steel fiber are jointly used as an admixture of concrete, there occur bonding forces between them. The addition of silica fume can effectively improve the fiber-matrix interface performance. Therefore, when silica fume and steel fiber are jointly used as admixture of concrete, the initial crack resistance and initial deflection of concrete can be effectively improved.

2.2. Flexural Toughness. As can be seen in Table 4 and Fig. 2a, the failure of reference concrete is sudden brittle failure. Once the reference concrete is cracked, it quickly loses its stability and is fractured. There are the pre-existing fractures and the microcrack in the concrete mixture. When the external force is applied to the concrete mixture, the stress concentration in the holes and cracks causes the crack propagation, and finally leads to the structural failure. Due to bridging of microcracks, the steel fiber will be able to transfer the load to the surrounding uncracked concrete in the process of loadbearing of the concrete mixture with steel fibers, thus improving the ability of preventing crack propagation, changing the crack orientation, and reducing the crack growth rate. Thus, steel fibers improve the strength and toughness of concrete. Under load action, the steel fiber-reinforced concrete specimens are cracked but not totally fractured. The specimen failure occurs not as a tensile fracture of the steel fiber, but as its pullout from concrete. 


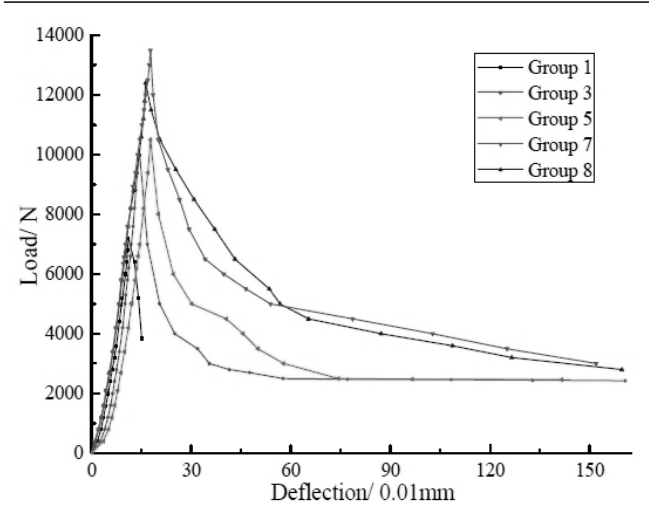

a

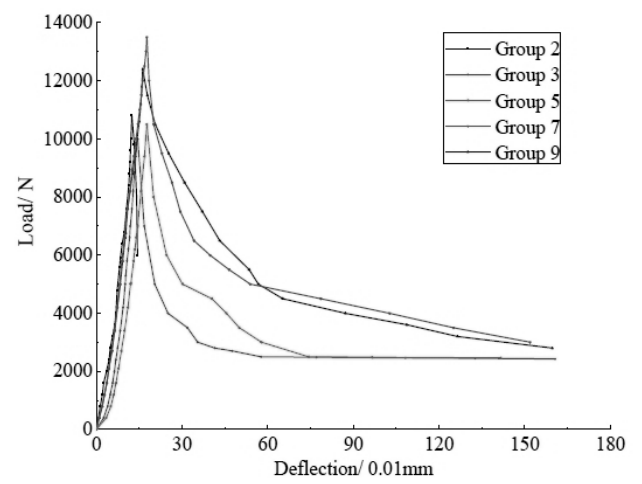

$\mathrm{b}$

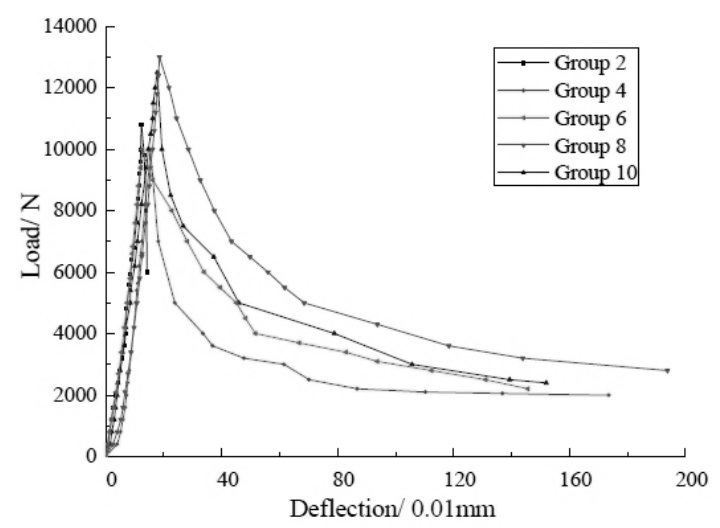

$\mathrm{c}$

Fig. 2. Load-deflection curve of wave shear type steel fiber concrete and reference concrete (a), wave shear type steel fiber concrete and silica fume concrete (b), and straight shear type steel fiber concrete and silica fume concrete (c).

As can be seen in Fig. 2a and $2 b$, with an increase in the content of wave shear type steel fiber, the flexural toughness indices $I_{5}, I_{10}$, and $I_{30}$ increase gradually. With increased distribution density of the steel fiber in the concrete, the pullout of these steel fibers requires higher loads: when the former property of mixture with straight shear type fiber and $10 \%$ of silica fume is increased from 40 to 50 and $60 \mathrm{~kg} / \mathrm{m}^{3}$, a plateau appears on its load-deflection curve, and its further drop is quite gradual, while the flexural toughness index $I_{5}$ changes from 4.98 to 5.21 and 5.28, $I_{10}$ from 9.45 to 9.73 and 9.82 , and $I_{30}$ from 25.65 to 26.87 and 27.02 , respectively. When the content of wave shear type steel fiber is increased from 40 to $50 \mathrm{~kg} / \mathrm{m}^{3}$, the flexural toughness index increases rapidly. When the content of wave shear type steel fiber is increased from 50 to $60 \mathrm{~kg} / \mathrm{m}^{3}$, the flexural toughness index increases slowly. Since variation trend of groups 6, 8, and 10 are similar to those of groups 5, 7, and 9, their description is omitted for brevity. As seen in Fig. $2 \mathrm{a}$ and $2 \mathrm{~b}$, the peak load of concrete in group 7 is the maximum, but the resistance to cyclic bending loading is not as good as that of group 9 up to certain deflection value.Afterwards, the bending fatigue resistance of group 7 was higher than that of group 9 . It shows that when the content of steel fiber reaches a certain limit, its further increase is no longer beneficial for the reinforced concrete strength. Insofar as the confinement effect of steel fibers is limited, after their deformation the section shrinks rapidly, which leads to the decrease in the adhesive interface and further weakens its reinforcing effect. 
The flexural toughness indices $I_{5}, I_{10}$, and $I_{30}$ of the concrete mixture with $10 \%$ of silica fume and wave shear type steel fiber of $60 \mathrm{~kg} / \mathrm{m}^{3}$ are close to those of a perfect elastic-perfectly plastic material. This shows that the applied mixing ratio is close to the latter material.

As seen from Fig. 2b, as as the silica fume concrete without steel fibers is cracked, its further fracture process is rapid. This implies that the silica fume alone without steel fiber has no significant effect on the flexural fracture toughness of the concrete mixture. The flexural toughness indices $I_{5}, I_{10}$, and $I_{30}$ of the concrete mixture with wave shear type steel fiber of $40 \mathrm{~kg} / \mathrm{m}^{3}$ are $4.86,9.26$, and 24.91 , respectively. So, steel fibers improve the flexural toughness index of concrete significantly. From groups 3 and 5, it can be understood that adding $10 \%$ of silica fume into the mixture with the same amount and shape of steel fiber resulted in the increase in the flexural toughness index $I_{5}, I_{10}$, and $I_{30}$ by $0.12,0.19$, and 0.74 , respectively. The flexural toughness index was partly improved, but not changed significantly. From Fig. 1b, it can be seen that the effect of straight shear type steel fiber and silica fume improved the flexural toughness of concrete similarly to that of wave shear type steel fiber and silica fume. In the strengthening effect of steel fiber silica fume concrete, the steel fiber is of first importance, while silica fume is an auxiliary component.

The pozzolanic reaction and microaggregate characteristics of silica fume can improve the interfacial transition zone between the cement paste and aggregate and increase the strength by pore structure refinement. Because silica fume has stickiness properties for steel fibers to a certain degree, adding both silica fume and steel fiber resulted in improving the fiber-matrix interface properties. Especially, when the fiber is pulled out, it takes more energy to pull out the steel fiber. So, adding silica fume increases the bending strength of steel fiber reinforced concrete to a certain degree, but not significantly.

The contrast analysis of steel fiber improves the first-crack strength and the flexural toughness of concrete: before the initial cracking, the concrete specimens is in an elastic stage; after the initial cracking, matrix unload and steel fiber load, the composites continue to work and are able to bear greater load until the steel fiber is pulled out. The energy consumption of steel fiber pull-out after the initial cracking is greater than that overcoming the limitation of steel fiber on matrix cracking before the initial cracking. So, the increased range of steel fiber on the flexural toughness of concrete is larger than that of steel fiber on the initial crack strength and initial deflection of concrete.

2.3. Steel Fiber Types. The flexural toughness index of wave shear type and straight shear type steel fiber reinforced concrete with silica fume was depicted in Fig. 3. Based on the results presented in Fig. 3, the increased range of wave shear type steel fiber on the strength of concrete is larger than that of straight shear type steel fiber on the strength of concrete. That is the toughening and reinforcing effect of wave shear type steel fiber on concrete is better. Different types of steel fiber lead to different bond strength of steel fiber and matrix. wave shear type steel fiber is modified (cross-section) fiber, the convex mark increases the anchoring force of steel fiber. The role of steel fiber in concrete matrix includes the bond strength and the grip strength. The grip strength of wave shear type steel fiber on concrete is greater that of straight shear type steel fiber on concrete. The pullout of wave shear type steel fibers requires a greater load. So, the toughening and reinforcing effect of wave shear type steel fiber on concrete is better. Under the condition of keeping the content of steel fiber, the proportion, the length and aspect ratio of steel fiber unchanged, the strength of concrete is only related to the influence coefficient of steel fiber on various bearing capacity, and the bearing capacity influence coefficient of wave shear type steel fiber reinforced concrete is larger than that of straight shear type steel fiber reinforced concrete. 


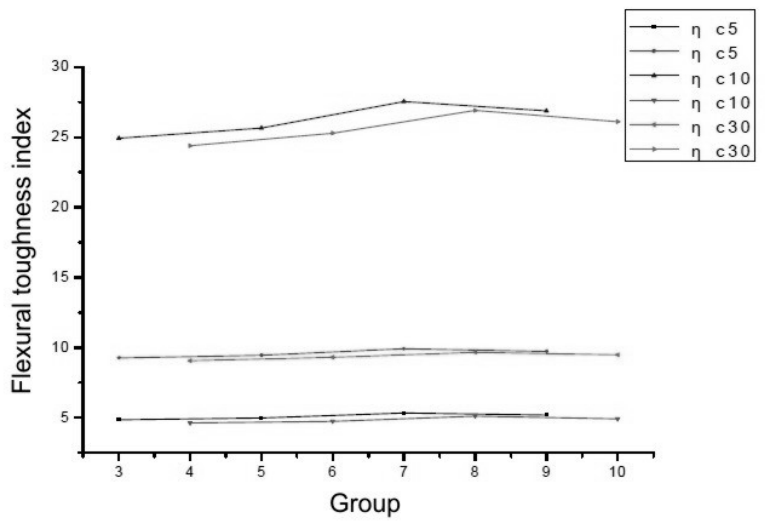

Fig. 3. The flexural toughness index of different types steel fiber reinforced concrete.

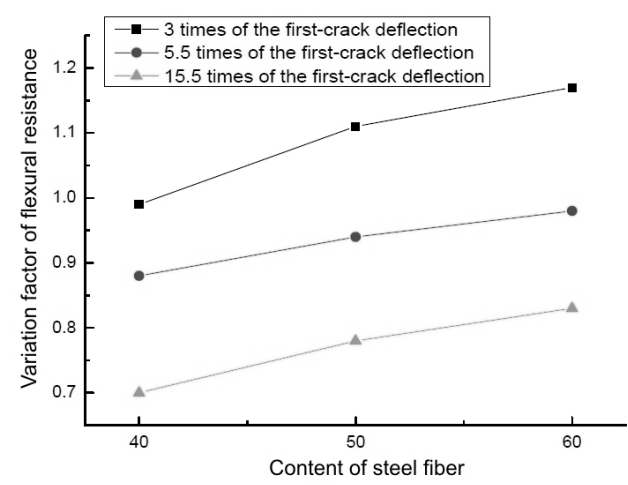

a

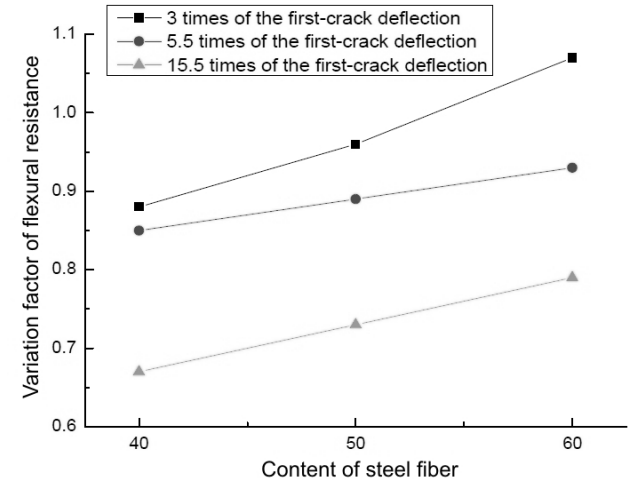

b

Fig. 4. Relationship between the content of wave shear type steel fiber (a) and straight shear type steel fiber (b) and the variation factor of flexural capacity of concrete.

2.4. The Variation Factor of Flexural Capacity. By comparing group 3 and group 5, group 4 and group 6 in Table 4, it can be concluded that under the condition of keeping the content of steel fiber, silica fume improved the variation factor of flexural capacity of specimens to a certain degree. Figure 4 depicts: with the increase of steel fiber content, the variation factor of flexural capacity of concrete specimens with silica fume content of $10 \%$ increases gradually. With the same amount of steel fiber, the variation factor of flexural capacity of wave shear type steel fiber reinforced concrete is slightly larger than that of straight shear type steel fiber reinforced concrete. According to the comprehensive analysis of $\xi_{m, n, 5}, \xi_{m, n, 10}$, and $\xi_{m, n, 30}$, the variation factor of flexural capacity of group 7 is the closest to " 1 ", so the flexural toughness of this concrete is close to that of elastic-perfectly plastic material. After the initial cracking of concrete, the bearing capacity of concrete increases further because of the bridging action of steel fiber. And with an increase in the steel fiber content, the ultimate bearing capacity of concrete specimens increases and the descent segment of load-deflection curve is gradual. Thus, a higher variation factor of flexural capacity can be obtained.

3. Engineering Application. The common shotcrete support was adopted in the design of the 1103 main roadway of Fucun coal mine in China. After the shotcrete support, the influence of dynamic pressure and other factors lead to the cracking and fracture of the roadway lining. So, this paper puts forward to adopting wet steel fiber silica fume shotcrete support to control the surrounding rock mass. 
The reinforcing and toughening effect of group 7 in above test is the best, so the mix proportion of concrete of group 7 in Table 3 is adopted. In addition, the steel fiber silica fume shotcrete thickness is the same as that of the original shotcrete layer with $100 \mathrm{~mm}$. The bolt support parameters are based on the original support scheme.

To investigate the effect of steel fiber silica fume shotcrete support to control the stability of the surrounding rock mass of roadway, two roadway sections named observation stations 1 and 2 were selected for measurements including shotcrete lining stress and roadway displacement.

3.1. Shotcrete Lining Stress. Select EBJ-C steel cord strain gauge to measure shotcrete lining stress. EBJ-C steel cord strain gauge was embedded in the roadway left side, roadway right side and roadway roof of two observation stations, respectively. The strain gauge is in the middle of the shotcrete lining. The measurements of shotcrete lining stress for the two observation stations are shown in Fig. 5.

Figure 5 depicts: the shotcrete lining stress at observation stations is less. The maximum stresses of the shotcrete lining in observation stations 1 and 2 are both in the roadway's left side and the maximum stresses are 0.6 and $0.5 \mathrm{MPa}$, respectively. From the change trend of the shotcrete lining stress in observation station 1 and observation station 2 , the stress of each observation station increases with the increase of time and finally tends to be stable. It shows that the shotcrete lining stress is smaller and tends to be stable rapidly, which is consistent with the monitoring results of roadway deformation.

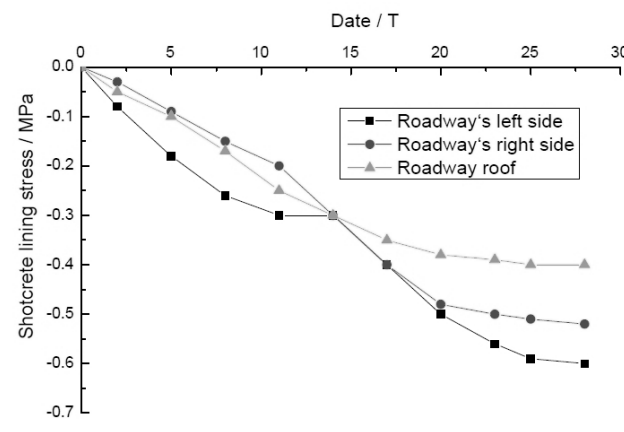

a

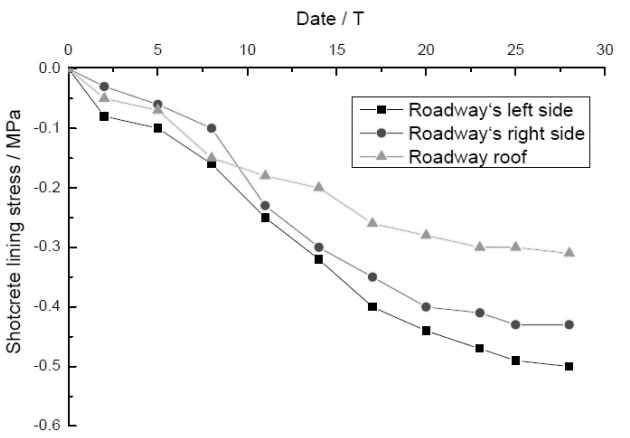

$\mathrm{b}$

Fig. 5. Shotcrete lining stresses of observation stations 1 (a) and 2 (b).
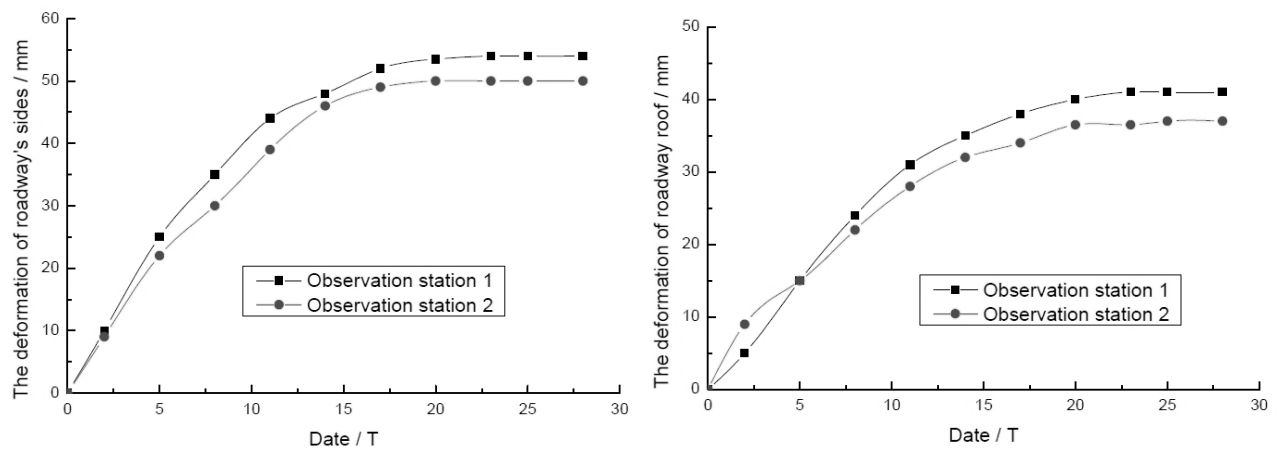

Fig. 6 Roadway deformations of observation stations.

3.2. Roadway Deformation. The deformations of the surrounding rock after the shotcrete support by steel fiber silica fume concrete are indicated in Fig. 6. The maximum deformations of the roadway's two sides in observation stations 1 and 2 are 52 and $50 \mathrm{~mm}$, 
respectively. The average rate of approximation of the roadway's two sides is $2.55 \mathrm{~mm} /$ day (mean value of two observation stations). The subsidence of the roadway roof in observation stations 1 and 2 are 41 and $37 \mathrm{~mm}$, respectively. The average subsidence rate of the roadway roof is $1.95 \mathrm{~mm} /$ day (mean value of two observation stations). The deformation of the roadway is small and the shotcrete lining has no crack. It shows that the system composed of the steel fiber silica fume shotcrete lining and the surrounding rock has good stability.

\section{Con clusions}

1. The addition of silica fume and steel fibers to concrete improves the first-crack load and the first-crack deflection parameters. With an increase in the steel fiber content, the first-crack load and the first-crack deflection of concrete increase gradually.

2. With an increase in the content of steel fiber, the flexural toughness indices $I_{5}, I_{10}$, and $I_{30}$ increase gradually. When the content of steel fiber reaches a certain value, its further growth has insignificant strengthening effect. The concrete mixture with $10 \%$ of silica fume used as cement replacement and wave shear type steel fiber of $60 \mathrm{~kg} / \mathrm{m}^{3}$ exhibits nearly ideal elastic-perfectly plastic material properties.

3. In the strengthening effect of steel fiber silica fume concrete, the steel fiber is of first importance, while silica fume is an auxiliary component. The reinforcing effect of wave shear type steel fiber on concrete is stronger than that of straight shear type one. The steel fiber effect on the flexural toughness of concrete is stronger than that on the initial crack strength and initial deflection of concrete.

4. With an increase in the steel fiber content, the variation factor of flexural capacity of concrete specimens with silica fume content of $10 \%$ increases gradually. With the same amount of steel fiber, the variation factor of flexural capacity of wave shear type steel fiber-reinforced concrete is slightly higher than that of straight shear type one.

5. Usage of wet steel fiber-silica fume shotcrete support to control the surrounding rock mass can effectively avoid the cracking and fracture of the roadway lining after the shotcrete support of ordinary concrete. Furthermore, it can improve the whole supporting effect of the anchor mesh shotcrete.

Acknowledgments. This research was fully funded by Student Science and Technology Innovation Fund Foundation of College of Mining and Safety Engineering in Shandong University of Science and Technology (KYKC17009).

1. G. Liu, L. Chen, W. Cheng, and Y. Huang, "Research on pump primers for friction reduction of wet-mix shotcrete based on precreating lubricating layer," Adv. Mater. Sci. Eng., 2017, 1-12 (2017), DOI: 10.1155/2017/3462074.

2. G. Liu and L. Chen, "Development of a new type of green switch air entraining agent for wet-mix shotcrete and its engineering application," Adv. Mater. Sci. Eng., 2016, 1-9 (2016), DOI: 10.1155/2016/6981091.

3. P. Teymur, S. Pala, and E. Yuksel, "Retrofitting of vulnerable reinforced concrete frames with wet-mixed shotcrete panels," Adv. Struct. Eng., 15, 1-14 (2012).

4. D. Niu, Y. Wang, R. Ma, et al., "Experiment study on the failure mechanism of dry-mix shotcrete under the combined actions of sulfate attack and drying-wetting cycles," Constr. Build. Mater., 81, 74-80 (2015).

5. N. Ranjbar, A. Behnia, B. Alsubari, et al., "Durability and mechanical properties of self-compacting concrete incorporating palm oil fuel ash," J. Clean. Prod., 112, 723-730 (2016).

6. M. Rostami and K. Behfarnia, "The effect of silica fume on durability of alkali activated slag concrete," Constr. Build. Mater., 134, 262-268 (2017). 
7. N. Ranjbar, M. Mehrali, M. Mehrali, et al., "Graphene nanoplatelet-fly ash based geopolymer composites," Cement Concrete Res., 76, 222-231 (2015).

8. N. Ranjbar, M. Mehrali, M. Mehrali, et al., "High tensile strength fly ash based geopolymer composite using copper coated micro steel fiber," Constr. Build. Mater., 112, 629-638 (2016).

9. T. Job and R. Ananth, "Mechanical properties of steel fiber-reinforced concrete," $J$. Mater. Civil Eng., 19, 385-392 (2007).

10. S. Iqbal, A. Ali, K. Holschemacher, and T. A. Bier, "Mechanical properties of steel fiber reinforced high strength lightweight self-compacting concrete (SHLSCC)," Constr. Build. Mater., 98, 325-333 (2015).

11. J. Li, C. Wan, J. Niu, et al., "Investigation on flexural toughness evaluation method of steel fiber reinforced lightweight aggregate concrete," Constr. Build. Mater., 131, 449-458 (2017).

12. S. Fallah and M. Nematzadeh. "Mechanical properties and durability of high-strength concrete containing macro-polymeric and polypropylene fibers with nano-silica and silica fume," Constr. Build. Mater., 132, 170-187 (2017).

13. M. Mastali and A. Dalvand, "Use of silica fume and recycled steel fibers in self-compacting concrete (SCC)," Constr. Build. Mater., 125, 196-209 (2016).

14. S Arivalagan, "Flexural behaviour of hybrid fibre (steel fiber and silica fume) reinforced self-compacting composite concrete members," World J. Eng., 11, No. 4, 323-330 (2014).

15. M. Gesoğlu, E. Güneyisi, R. Alzeebaree, and K. Mermerdaş, "Effect of silica fume and steel fiber on the mechanical properties of the concretes produced with cold bonded fly ash aggregates," Constr. Build. Mater., 40, 982-990 (2013).

16. G. Liu, W. Cheng, and L. Chen, "Investigating and optimizing the mix proportion of pumping wet-mix shotcrete with polypropylene fiber," Constr. Build. Mater., 150, 14-23 (2017).

17. W. Cheng, G. Liu, and L. Chen, "Pet fiber reinforced wet-mix shotcrete with walnut shell as replaced aggregate," Appl. Sci., 7, 345 (2017).

18. L. Liu and J. Zhang, "Thermal insulation composite material for governance of underground thermal hazard and its application," J. Shandong Univ. Sci. Technol. (Natur. Sci. Ed.), 36, 46-53 (2017).

19. S. Hu, Y. Tan, H. Zhou, et al., "Impact of bedding planes on mechanical properties of sandstone," Rock Mech. Rock Eng., 50, No. 8, 2243-2251 (2017).

Received 15. 09. 2017 